\title{
Preguntas a Hilda Sabato
}

\section{( Sol Serrano ${ }^{1}$}

Universidad Católica de Chile, Chile. Correo electronico: sserrano@uc.cl

Artículo recibido: 16 de junio de 2021 Aprobación final: 30 de septiembre de 2021

\section{Resumen}

El ensayo analiza el último libro de Hilda Sabato y plantea dos grandes interrogantes. El primero apunta a desentrañar el motivo por el cual las independencias hispanoamericanas no han formado parte de la gran narrativa sobre las revoluciones democráticas del Atlántico Norte. ¿Esta situación se vincula con las hegemonías de la producción historiográfica internacional? El segundo se refiere a su propia experiencia en la formación de redes, circulaciones y prácticas de la disciplina histórica en la renovación teórica y metodológica de la historia política, que permitió incluir las Independencias como parte del amplio fenómeno de la política moderna.

Palabras clave: Política Moderna, Producción historiográfica, Hegemonía Nor-Atlántica, Nueva Historia Política.

\section{Questions to Hilda Sabato}

\begin{abstract}
The essay analyzes Hilda Sabato's last book (Repúblicas del Nuevo Mundo. El experimento político latinoamericano del siglo XIX, Buenos Aires: Taurus/Penguin Random House, 2021) and poses two main questions. The first one points to the reasons why Spanish American independences have not been part of the narratives about the Atlantic democratic revolutions. Is this situation a consequence of
\end{abstract}

1 Escribo estas palabras en cuarentena en el campo sin acceso a mis libros ni a la biblioteca, solo a Internet. Utilizo el texto en su versión en inglés. 
the hegemonic trends in international historiographical production? The second refers to Hilda Sabato's own experience in the formation of networks, circulations, and practices of the discipline leading to the theoretical and methodological renewal of political history, which has recently placed those independences as important topics within the broad history of political modernity.

Keywords: Modern Politics, Historiography, Global North Hegemony, New Political History.

No es de extrañar que haya sido la historiadora argentina Hilda Sabato quien escribiera este libro que marca un hito en los caminos de la renovación de la historia política y del estudio de la "modernidad política" en América Latina.

Marca un hito porque recoge la rica historiografía, vibrante la llama ella, de las tres últimas décadas -de la cual forma parte destacada- y propone una interpretación de conjunto, propia, depurada y destilada. Marca un hito también en las formas de producción del conocimiento histórico en el campo internacional. Para decirlo gráficamente -sin ser una reivindicación regionalista ni de género-, es digno de análisis que este texto se haya publicado primero en inglés y luego en español, y que lo escribiera una historiadora hispanoamericana y no un varón anglosajón.

El objetivo de Hilda Sabato es situar las construcciones republicanas en América Hispana en el amplio marco de la formación de la "política moderna". En aquel paso tan incierto y complejo del advenimiento de la legitimidad del poder basado en la soberanía popular en oposición a la legitimidad religiosa, que comprende a individuos iguales ante la ley en oposición a los derechos adscritos a los cuerpos propios de las sociedades de Antiguo Régimen. Quiere llamar la atención sobre la diversidad de respuestas de las sociedades que vivieron dicho proceso y destacar la opción por la Republica en el Hemisferio Norte tomando en consideración la multiplicidad de opciones abiertas, desde la regresión monárquica a las monarquías constitucionales. Claro está, se señala, que las formaciones de las repúblicas en la América Hispana suelen ser soslayadas. O más bien omitidas porque la historiografía nor-atlántica y también parte de la domestica, especialmente en el siglo XX, no las calificaron como repúblicas. Ahí reside la profunda novedad e importancia de la nueva historia política que propone otras categorías teóricas y metodológicas para revisitar las complejidades de ese proceso en Europa y en Estados Unidos, complejidades que parecían haber sido solo una condición del sur.

Hilda Sabato nos cuenta en la Introducción que este corto ensayo es fruto de una larga historia. Pues bien, la interesante iniciativa del Instituto Ravignani de convocar a este dossier, del que me honra y agradezco ser parte, nos da la oportunidad para que se explaye en ella. Hoy, cuando nos interesa más que nunca la historia "conectada", la circulación de las ideas y sus distintas apropiaciones, las prácticas y formas de construcción del conocimiento adquieren un gran valor hermenéutico. La experiencia de Hilda Sabato es especialmente rica como fuente de esta historiografía. Conociendo su sobriedad, no puedo pedirle directamente 
que haga un ejercicio de "ego-histoire", sino un relato de su trayectoria. Pedirle que sea "fuente" de un itinerario intelectual muy rico.

Antes de pasar a mis preguntas, enunciaré algunos comentarios. El texto estudia los "experimentos republicanos" a través de la indagación de los componentes de la política en la relación entre pueblo y gobierno luego de la adopción de la soberanía popular como principio fundante del poder. Ante numerosos estudios que versan sobre las elites o los sectores populares, aquí se opta por la relación entre ambos en el periodo entre 1820 y 1870. El problema que articula el texto, entonces, es este cambio de la soberanía y las nuevas relaciones que genera en la sociedad a través de tres dimensiones privilegiadas de la vida política del periodo: las elecciones, la ciudadana armada y la milicia y la "opinión publica”. El texto demuestra con creces cuan acertadas son las tres. Señala que no son exhaustivas, obviamente. Pero hay una dimensión, a mi juicio, que es sustantiva al tema estudiado, pues la nueva soberanía se define por el paso de lo religioso a lo civil. Es la secularización de la legitimidad política en una monarquía católica. El tema religioso no se trata en el libro salvo en algunas referencias a las asociaciones católicas rurales, al poder de la Iglesia como corporación que las repúblicas buscan someter a la ley civil. Ello habría despertado enormes pasiones que dieron vigor a la participación política. El término "secularización" no aparece, como bien lo indica el índice temático. Sin embargo, una de las grandes originalidades de estas repúblicas fue que en sus inicios se mantuvieron católicas. Las revoluciones no fueron contra la Iglesia -la mayoría de esa elite política era regalista- sino propiamente contra la monarquía, y con ello disolvió el vínculo entre monarquía y catolicismo propio de Europa y de Roma inaugurando unas republicas católicas de corta vida, pero que dieron paso a una laicización del Estado que, exceptuando el caso de México y en menor medida el de Colombia, fue un proceso de negociación política bastante exitosa. La religión es uno de los grandes temas políticos del siglo XIX en el Occidente católico y que, insisto, la mayoría de América Hispana resolvió de manera especialmente original y con mucha menor violencia que otros casos europeos. No es una crítica que Hilda Sabato no considerara el problema religioso dentro de sus "entradas" a la nueva política, pero podría haber sido relevado, porque efectivamente está en el corazón de su planteamiento.

En la línea de las particularidades de la política de esta región y de su larga representación como campo de violencia, este libro abre preguntas sobre el periodo posterior. El brillante ensayo final postula que los experimentos republicanos dieron paso hacia fines de siglo al periodo del dominio del imperialismo y nacionalismo. Este texto entrega herramientas intelectuales para seguir haciendo ese ejercicio como preguntarse si los nacionalismos latinoamericanos no admiten importantes distinciones respecto del caso europeo. Al menos por los niveles de racismo y de violencia con los que Europa marco la triste historia del siglo XX.

Dicho lo anterior, puedo volver a mi motivación original, la historia de nuestra autora. 


\section{Primera pregunta}

El texto discute con una larga historiografía que ha considerado a la política hispanoamericana en el siglo XIX como una modernización fallida en la cual el liberalismo no logró asentarse por diversas razones, como la herencia colonial hasta formas pre modernas de resistencia. "Esta literatura produjo algunas de las interpretaciones más convincentes sobre el pasado latinoamericano y son todavía muy influyentes y persuasivas” (p. 7). Por ello, deduzco, estas repúblicas han estado ausentes de las grandes narrativas sobre las revoluciones modernas. La pregunta, entonces, es sobre sus reflexiones sobre esta ausencia.

Me atrevo a aventurar algunas impresiones a modo introductorio. A mi juicio, América Hispana ha estado "dolosamente" ausente, en parte porque a la teoría política surgida de las revoluciones Nor-atlánticas no le generó interés. Ha sido vista, a lo más, con desdén porque se trataba de colonias de una metrópolis decadente. Inglaterra se levantaba como el primer poder y Francia seguía siendo la "luz". Burke escribe sobre Francia y Tocqueville sobre Estados Unidos. Ninguno de su estatura habría escrito sobre México. Este mundo no representaba el futuro cuando se vivía el momento estelar de la invención del futuro. Y un tema no menor: esta zona del mundo era católica. Por tanto, refractaria del cambio radical que era el del origen de la soberanía. La academia norteamericana empezó a interesarse en el mundo hispano en la segunda mitad del XIX y se concentró en el periodo del gran y poderoso imperio. El estudio de Iván Jaksic (2007) nos permite seguir esta agenda historiográfica. Prescott deslumbró al público con sus estudios sobre la conquista de México y Perú. Estaban buscando -lo han seguido haciendo- los motivos de la potencia y de la decadencia de los imperios. El español había decaído por su intolerancia religiosa y su codicia, algo que no le sucedería a la otra América protestante y trabajadora. El momento de oro de la importancia del campo fue la Revolución Cubana. Tanto desde el desarrollismo como del progresismo de izquierda, se reprodujo por muy diversas razones y con distintos culpables, la imposibilidad de la modernidad en la región. Recuerdo en mis años de estudiante dos textos que me marcaron en realidad porque me molestaron. Uno, The Poverty of Progress. Latin America in the Nineteenth Ventury, de E. Bradford Burns, publicado 1980 (Burns, 1980), donde la historia del siglo se muestra como el conflicto entre unas elites retóricamente modernas, que se abren a la modernización con grandes ganancias y succionan las culturas de las comunidades locales en un proyecto que los destruye y empobrece. Era una crítica "culturalista-popular" a la modernización y tuvo eco en las universidades y entre los intelectuales latinoamericanos. Octavio Paz lo alabó especialmente. Dos años después se publicó la segunda edición (que es la que importa) del texto, a cargo de Howard J. Wiarda, titulado Politics and Social Change in Latin America. The Distinct Tradition. (Wiarda 1982). Wiarda es crítico del eurocentrismo dominante en los estudios sobre América Latina al utilizar conceptos exógenos, carentes de capacidad explicativa porque no comprendían sus "instituciones tradicionales" que habían probado su persistencia y su apego al poder. "Whether it is African tribalism, Indian caste associations, Islamic theocracy, or Latin American personalism, Catholicism, and familism..., las instituciones tradicionales se acomodaban, 
se resistían, se entrelazaban pero no se transformaban en instituciones modernas (Wiarda, 1982:7).Esta representación me causaba suspicacia. Había que comprender la región desde la no-modernidad porque solo se nos podía mirar -a veces sentía que necesitaban mirarnos- como opresores, oprimidos o revolucionarios. Esa mirada no era tan distinta a la de muchos intelectuales latinoamericanos. La versión más caricaturesca de una victimización flagrante -uno de los ensayos más leídos por los estudiantes en Estados Unidos y en la región- era para mí Las Venas Abiertas de América Latina, de Eduardo Galeano, publicado en 1971, cuyos 50 años fueron ampliamente celebrados por varias editoriales.

Por otra parte, América Latina suele ser considerada por universidades anglosajonas, editoriales y revistas especialidades estrictamente como una región, y a su vez se la encierra en sí misma. Es más difícil encontrarla como un "caso" en torno a problemas, procesos, temas o conceptos. El auge de los estudios post coloniales, aunque ha tenido impacto en la historiografía latinoamericana, tiende por su mismo origen a referirse a las experiencias de la descolonización en Asia, África y Oceanía posteriores a la Segunda Guerra Mundial más que a procesos de descolonización como los del Imperio Español. Pareciera que América Latina se escurre de estos grandes procesos quizá precisamente por la menor relevancia de España en la producción de conocimiento. El texto de Hilda Sabato marca la tendencia opuesta y la bibliografía sugiere un proceso de cambio. ¿O no?

\section{Segunda pregunta}

La renovación de la historia política y el estudio de la "política moderna" comprende diversos orígenes y disciplinas. Un hito muy importante creo que fueron los bicentenarios de la Independencia de Estados Unidos, pero mucho más el de la Revolución Francesa, donde cristalizó la crítica al estructuralismo. La proposición de fondo era que las revoluciones habían sido fundamentalmente políticas y no un reflejo de la estructura económica social ni tampoco fruto mecánico de las "ideas" de la Ilustración, sino de circulación en nuevas formas de sociabilidad igualitarias y la formación del espacio público. Se rescato a los actores y el tiempo corto. Quizás hay dos textos emblemáticos que fueron Penser la Révolution, de Francois Furet, cuya primera edición es de 1978, y los cuatro volúmenes publicados entre 1987 y 1994 de The French Revolucion and the Creation of Modern Culture, cuyos editores y autores principales fueron Keith M. Baker y Lucas Colin, especialistas anglosajones, el mismo Francois Furet y Mona Ozouf (Furet, 1987; Varios Autores, 1987). El gran mérito de François-Xavier Guerra, tal como lo señala Hilda Sabato, fue ser posiblemente el primero en proponer esa amplia interpretación en el mundo hispano de ambos lados del Atlántico. Guerra ya había formulado nuevas proposiciones teóricas y metodológicas de la historia política en su monumental obra Le Mexique: De l 'Áncien Regime a la Révolution, de 1985, y adquirieron su expresión madura en su gran obra Modernidad e Independencias en 1992. En su obituario, Hilda Sabato (2003) le otorga a Guerra "un lugar central en la renovación de la historia política” que marcó la historiografía sobre la transición del 
Antiguo Régimen en Iberoamérica (sabato, 2003: 7). Tal como ahí lo recuerda, Guerra fue un formador de historiadores(ras) y un incansable organizador de libros y encuentros transatlánticos que forjaron redes amplias y porosas. La bibliografía del texto de Hilda Sabato muestra bien esa inflexión y las muchas corrientes que convergen en su propia obra y en su trayectoria intelectual.

Hilda Sabato tiene un recorrido historiográfico muy amplio que vale la pena historiar. Lamento no ser quién para hacerlo. Sabemos que su gran maestro fue Tulio Halperin Donghi; que se inició en la historia social y económica, y que el revisionismo marxista inglés debe haber sido importante en su tesis doctoral defendida 1981 en la Universidad de Londres. Luego fue derivando hacia el estudio de los sectores populares movilizados en Argentina. Miro rápidamente su biografía en "Google”, su notable carrera la conozco, aunque no entera, solo busco sus peregrinaciones académicas y años de publicación. Durante la década del ' 90 hizo largas estadías en los más importantes centros universitarios estadounidenses y europeos y es en esos años cuando publica el primer artículo ya propiamente de historia política que la lleva hacia el tan famoso libro sobre la política en las calles de Buenos Aires. Las fuentes intelectuales de Hilda son amplias, diversas y eclécticas. Pensé si había escrito algo sobre estos tránsitos y encontré un artículo suyo que parecía perfecto para mi indagación: "Saberes y Pasiones del Historiador. Apuntes en primera persona” (Sabato, 2007). Me lo envió gentilmente. Es una reflexión audaz y honesta sobre la historia reciente y las tensiones epistemológicas que genera o puede generar en el historiador haciendo una diferenciación siempre bienvenida entre historia y memoria. Pero no era lo que yo buscaba. Sin embargo, una cita suya de Michel de Certau me permitió hacer biográfico lo epistemológico:

cada resultado individual se inscribe en una red de elementos estrechamente interdependientes cuya combinación dinámica forma la historia en un momento dado (...). Es el producto de un lugar.

Entonces le pregunto por sus lugares recorridos. 


\section{Q Bibliografía}

" Burns, B. (1980). The Poverty of Progress. Latin America in the Nineteenth Century. Berkeley and Los Angeles: University of California Press.

" Furet, F. (1978). Penser la Révolution Francaise. Paris: Editions Gallimard.

" Galeano, E. (1971). Las Venas Abiertas de América Latina. México: Siglo XXI Editores.

" Guerra, F. X. (1985), Le Mexique: De I 'Áncien Regime a la Révolution, Paris: L'Harmattan.

" Guerra, F. X. (1992), Modernidad e independencias. Ensayos sobre las revoluciones hispánicas. Madrid: Mapfre.

" Jaksic, I. (2007). Ven conmigo a la España lejana: los intelectuales norteamericanos ante el mundo hispano,1820-1880. Santiago: FCE.

"Sabato, H. (2003). Francois Xavier Guerra (1942-2002). Prismas-Revista de Historia Intelectual, 7( 2), pp. 7-8.

"Sabato, H. (2007), "Saberes y pasiones del historiador. Apuntes en primera persona" Marina Franco y Florencia Levin (comps.): Historia reciente. Perspectivas y desafíos para un campo en construcción. Buenos Aires: Paidós.

"Sabato, H. (2018), Republics of the New World. The Revolutionary Political Experiment in 19th-Century Latin America. Princeton, New Jersey: Princeton University Press.

" Varios Autores (1987-1994). The French Revolution and the Creation of Modern Political Culture. Oxford: Pergamon,Vol. I-IV.

"Wiarda, H. J. (ed.) (1982). Politics and Social Change in Latin America. The Distinct Tradition, The University of Massachusetts Press, Second Revised Edition. 